\title{
Evaluation of a diltiazem cream preparation for estimation of degradation behavior
}

\author{
Bahar KÖKSEL ÖZGEN ${ }^{1}$ (D), Burcu BULUT ${ }^{1}$ (D), Nagehan SARRAÇOĞLU 1 (D), \\ Asuman AYBEY DOĞANAY 1 (D), Onur PINARBAŞLI 1 * iD \\ 1 İlko Pharmaceuticals, Research and Development Center, Ankara, Turkey. \\ * Corresponding Author. E-mail: opinarbasli@ilko.com.tr (O.P.); Tel. +90-312-248 6800.
}

Received: 01 June 2020 / Revised: 01 September 2020/ Accepted: 17 September 2020

\begin{abstract}
Diltiazem cream, which is used in chronic anal fissure (CAF) treatment, is known to be susceptible to hydrolysis and degradation in aqueous solutions. The major pathway of degradation is o-deacetylation which leads to formation of 'desacetyl diltiazem' and this study focuses on this degradation mechanism. In this study, degradation of diltiazem incorporated into an oil-in-water cream base was investigated. It was especially aimed to show the effect of the formulation preparation procedure on impurity formation during the diltiazem cream formulation. In this regard, preliminary studies were performed to optimize the formulation parameters for stability. The outcome of these studies was applied to the preparation procedure; the compositions of excipients were kept constant while the order of addition of excipients to the aqueous phase and the mixing time were varied. To our knowledge, there is no study published regarding the relation between this degradation and the formulation process. Formulations were characterized in terms of formation of the desacetyl diltiazem impurity with a validated stability indicating HPLC method. The cream formulation with the highest stability was obtained through mixing propylene glycol and water first and adding diltiazem active substance in the final step of formation of aqueous phase with a shortened stirring time. This preparation procedure exhibited reduced desacetyl diltiazem impurity formation.
\end{abstract}

KEYWORDS: Diltiazem; cream dosage form; formulation; desacetyl diltiazem impurity.

\section{INTRODUCTION}

Diltiazem hydrochloride, chemically known as 1, 5-benzothiazepin-4(5H)-one, 3-(acetyloxy)-5-[2(dimethylamino) ethyl]-2, 3-dihydro-2-(4-methoxyphenyl), monohydrochloride, is a benzothiazepine calcium channel blocking agent and vasodilator. It is commonly used to treat cardiovascular diseases such as angina pectoris, hypertension, and cardiac arrhythmias that lowers the blood pressure and has effect on cardiac conduction $[1,2,3]$.

Generally, oral preparations of diltiazem hydrochloride are used to treat angina and hypertension and topical form is known to be used in the treatment of chronic anal fissure (CAF) [1, 4, 5]. As suggested by Dhawan and Chopra, 2\% topical diltiazem hydrochloride is the first line treatment in case of CAF [6]. It is used to promote the healing and reduce symptoms of an anal fissure. It works by relaxing the muscle around the anus (the anal sphincter). This reduces pressure and increases blood flow to the area to allow healing to occur $[7,8]$. The usage of this product has been searched in clinical trials since 2000 [5].

In the literature, there are some problems related to diltiazem hydrochloride topical forms; especially, the formulations are generally unstable with the formation of the main degradation product desacetyl diltiazem [9, 10]. Desacetyl Diltiazem (Diltiazem EP Impurity F) is a metabolite of Diltiazem. The in vitro degradation of diltiazem hydrochloride is potentiated in acidic medium and at high temperatures. This degradation product (desacetyl diltiazem) has about $50 \%$ of the potency of diltiazem hydrochloride as a vasodilator [9]. Degradation is undesirable as it results in loss of activity, and leads to formation of undesirable impurities of negligible activity. Consequently, formation of this impurity causes a decrease in the vasodilator activity of the formulations for cutaneous application. To our knowledge, there was no study published regarding the relation between this degradation and the formulation process.

How to cite this article: Köksel Özgen B, Bulut B, Sarraçoğlu N, Aybey Doğanay A, Pınarbaşlı O. Evaluation of a diltiazem cream preparation for estimation of degradation behavior. J Res Pharm. 2021; 25(1): 13-21. 
Therefore, there was a need for a stable topical diltiazem formulation which may be an alternative to Anoheal@ 2\% Cream in topical treatments. This study was carried out with the aim to develop a stable formulation of diltiazem hydrochloride cream dosage form by lowering the formation of the main degradation product desacetyl diltiazem during the formulation process. The main objective of this study was to exhibit the effect of the formulation preparation procedure on impurity formation and develop a stability-indicating method in order to perform the stability studies.

\section{RESULTS AND DISCUSSION}

\subsection{Analytical method validation studies}

The HPLC method was validated by a standard validation procedure. Selectivity of the method was tested for all impurities mentioned in the EP monograph. Selectivity for analytes in reference standards, sample solution, spiked sample solution and placebo solution were investigated. Representative chromatograms of diltiazem cream sample solution spiked with impurities (1-oxide, cyclic, desacetyl diltiazem, trans diltiazem and acetyl cyclic impurities) are given in Figure 1. As can be seen from the chromatogram, no interference was found between diltiazem and related substances. In addition, the peaks from the placebo did not interfere with diltiazem or its related substances.

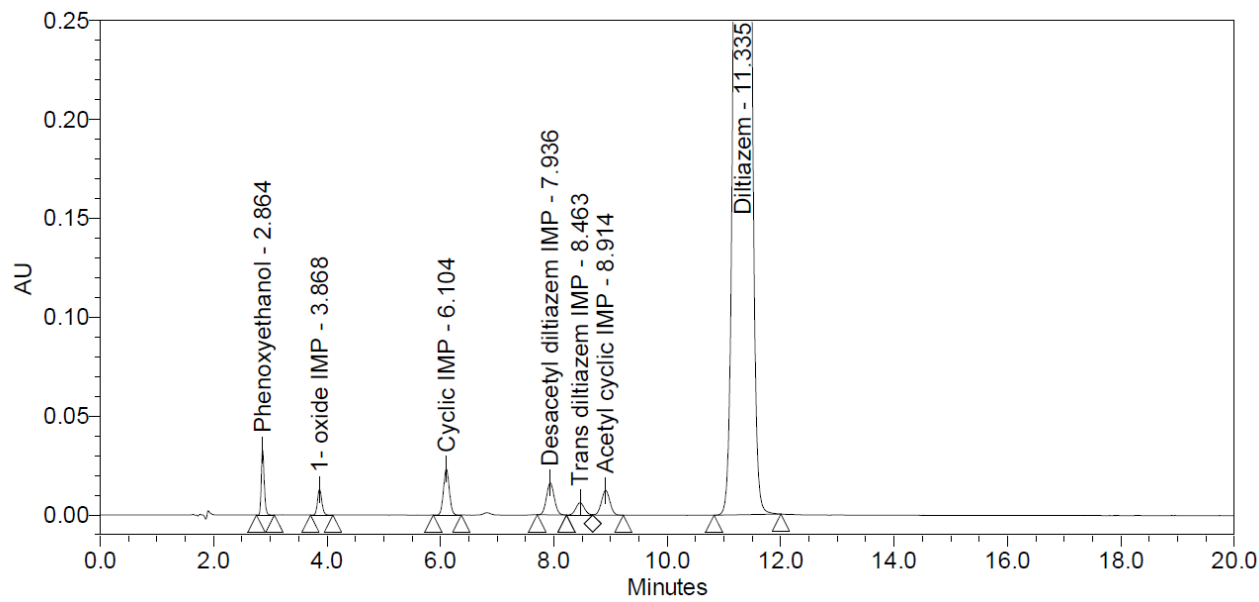

Figure 1. Representative chromatograms of Diltiazem cream sample spiked with impurities (1-oxide, cyclic, desacetyl diltiazem, trans diltiazem and acetyl cyclic impurities).

Linearity of the method was determined using standard solutions in the $20 \%$ to $120 \%$ of the specification levels corresponding to a concentration range of $0.4 \mu \mathrm{g} / \mathrm{mL}-2.4 \mu \mathrm{g} / \mathrm{mL}$ for diltiazem active substance and desacetyl diltiazem impurity. According to the constructed calibration curve, the obtained correlation coefficients were higher than 0.99 for both diltiazem active substance and desacetyl diltiazem impurity. The results indicate that the response is linear over the proposed range.

The LOD and LOQ concentrations were found to be $0.04 \mu \mathrm{g} / \mathrm{mL}$ and $0.14 \mu \mathrm{g} / \mathrm{mL}$ for diltiazem; 0.022 $\mu \mathrm{g} / \mathrm{mL}$ and $0.072 \mu \mathrm{g} / \mathrm{mL}$ for desacetyl diltiazem impurity, respectively.

Precision was demonstrated by evaluating relative standard deviation of system precision runs and method precision runs. For system precision, $2 \mu \mathrm{g} / \mathrm{mL}$ diltiazem standard solution was prepared and six consecutive HPLC injections were made. Relative standard deviation (RSD) between the peak areas of diltiazem was found to be $0.95 \%$. For method precision, six sample solutions with $2 \mu \mathrm{g} / \mathrm{mL}$ desacetyl diltiazem impurity addition were prepared and analyzed. RSD between the desacetyl diltiazem peak areas is $3.51 \%$. The results were found to be within limits $(<4 \%)$.

The accuracy of the method was determined by adding known amount of desacetyl diltiazem impurity to sample solution. The spiked solutions were prepared at three desacetyl diltiazem concentration levels of $20 \%, 100 \%$ and $120 \%$; corresponding to $0.4 \mu \mathrm{g} / \mathrm{mL}, 2.0 \mu \mathrm{g} / \mathrm{ml}$ and $2.4 \mu \mathrm{g} / \mathrm{ml}$. The recovery values were calculated. The desacetyl diltiazem impurity was recovered from all three levels with mean recovery value of $100.1 \%$ with RSD value of $3.84 \%$.

According to method validation results, the HPLC method meets all requirements for validation. This method was shown to be specific for diltiazem in the presence of degradation products. 


\subsection{Formulation studies}

Assay of diltiazem active substance, phenoxyethanol preservative and analysis of related substances were done for Formulation A, B, C and D. The results are given in Table 1.

Table 1. Results of assay and related substances for diltiazem hydrochloride cream formulations $(n=6)$.

\begin{tabular}{lcccc}
\hline & \multicolumn{2}{c}{ Assay \% } & \multicolumn{2}{c}{ Related Substance \% } \\
\cline { 2 - 5 } & Diltiazem & Phenoxyethanol & $\begin{array}{c}\text { Desacetyl } \\
\text { diltiazem Imp. }\end{array}$ & Total Imp. \\
\hline Formulation A & $98.7 \pm 0.88$ & $100.2 \pm 1.8$ & $1.2 \pm 0.26$ & $1.2 \pm 0.27$ \\
Formulation B & $99.0 \pm 1.2$ & $99.4 \pm 0.95$ & $1.1 \pm 0.21$ & $1.1 \pm 0.20$ \\
Formulation C & $100.4 \pm 1.3$ & $99.8 \pm 1.1$ & $0.09 \pm 0.01$ & $0.09 \pm 0.01$ \\
Formulation D & $99.6 \pm 0.77$ & $100.5 \pm 0.91$ & $0.08 \pm 0.01$ & $0.08 \pm 0.01$ \\
\hline
\end{tabular}

The active substance content for Formulations A - D were found to be in limits 95-105\%; however, in accordance with the performed studies it is possible to conclude that the diltiazem hydrochloride is more susceptible to degradation in formulation A and B, especially in formulations where it is mixed directly with water. The active substance is hydrolyzed and degrades to desacetyl diltiazem impurity. In Formulation $C$ and $\mathrm{D}$, the amount of desacetyl diltiazem impurity is significantly decreased demonstrating the effect of the addition of propylene glycol into water prior to mixing with the active substance. In addition, in Formulation $\mathrm{C}$ and $\mathrm{D}$, the effect of mixing time on degradation product can be observed. The addition of the diltiazem active subtance at the last step in the formation of the aqueous phase shortened the time which the active substance was exposed to aqueous phase mixing, thus minimizing degradation.

When all experimental results were evaluated, Formulation D was selected as the optimized formulation on the basis of its degradation behavior as shown in Table 1. This is achieved by dissolving diltiazem hydrochloride active substance in propylene glycol and water mixture instead of directly dissolving in water and reducing the mixing time of the process. Therefore, Formulation D was used for optimum formulation for the further studies.

\subsection{Performance studies}

The performance studies were applied to Formulation D and the results were considered acceptable after all characterization studies;

\subsubsection{Appearance}

The examined cream formulation was white in color, odorless, smooth and semi-solid structured with a homogeneous texture.

\subsection{2. $\mathrm{pH}$ measurement}

The $\mathrm{pH}$ of the examined cream formulation was $5.24 \pm 0.04$. The $\mathrm{pH}$ data showed that the cream formulation was suitable for damaged skin applications.

\subsubsection{Viscosity}

The mean viscosity of the cream obtained from Formulation D was $1540000 \pm 90000 \mathrm{cP}$. Apparent viscosity was stable over the course of the study.

\subsubsection{Microbiological test}

The cream of Formulation D was within recommended microbial specification limits. Total aerobic microbial count was lower than $10^{3} \mathrm{cfu} / \mathrm{g}$, total combined yeasts/molds count was lower than $10^{2} \mathrm{cfu} / \mathrm{g}$ and absence of escherichia coli/g was provided. The cream formulation does not exhibit microorganism growth.

\subsubsection{In vitro permeation studies}

The amounts of diltiazem released through Strat-M membranes from test product (Formulation D) and reference product are compared in Figure 2. As a result of the analysis, it was found that the reference product and the test product showed a similar profile according to the graph obtained from the amount of material passing through unit $\mathrm{cm}^{2}$. According to FDA (1997; Shah et al., 2013), acceptance criteria of the in vitro permeation studies is $75 \%-133.33 \%$; the ratio of slopes for test product and reference product is $81.8 \%$. 


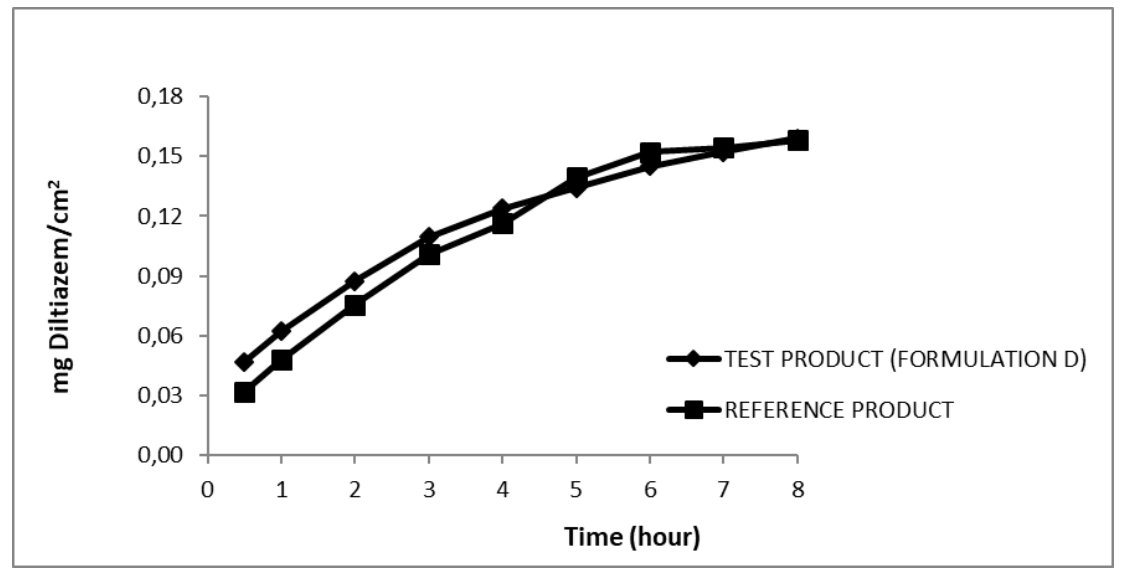

Figure 2. In vitro permeation profile of Test product (Formulation D) and Reference Product.

\subsection{Forced degradation and stability studies}

Forced degradation studies for the drug product were performed to understand degradation mechanisms and potential degradation products. To achieve this, the cream samples were exposed to acid hydrolysis $\left(1 \mathrm{~N} \mathrm{HCl}, 5 \mathrm{hr}\right.$, at $\left.25^{\circ} \mathrm{C}\right)$, alkali hydrolysis $\left(1 \mathrm{~N} \mathrm{NaOH}, 5 \mathrm{hr}\right.$, at $\left.25^{\circ} \mathrm{C}\right)$, oxidative degradation $\left(1 \% \mathrm{H}_{2} \mathrm{O}_{2}\right.$, $5 \mathrm{hr}$, at $25^{\circ} \mathrm{C}$ ), thermal degradation (samples placed in an oven at $80^{\circ} \mathrm{C}$ for 3 days) and humidity degradation $\left(75 \% \mathrm{RH}, 40^{\circ} \mathrm{C}, 3\right.$ days) conditions. The results are given in Table 2 . In the formulation examined by forced degradation, it was observed that the active substance was highly open to degradation.

Table 2. Results of forced degradation studies for Formulation D.

\begin{tabular}{|c|c|c|c|}
\hline Stress Conditions & $\begin{array}{c}\text { Recovered } \\
\text { Diltiazem \% }\end{array}$ & $\begin{array}{c}\text { Desacetyl } \\
\text { impurity \% }\end{array}$ & $\begin{array}{c}\text { Total } \\
\text { Impurity \% }\end{array}$ \\
\hline $1 \mathrm{~N} \mathrm{HCl}$ & 72.2 & 27.7 & 27.8 \\
\hline $1 \mathrm{~N} \mathrm{NaOH}$ & 25.2 & 74.7 & 74.8 \\
\hline $1 \% \mathrm{H}_{2} \mathrm{O}_{2}$ & 78.8 & 4.1 & 21.2 \\
\hline Humidity; $40^{\circ} \mathrm{C} \& 75 \%$ RH & 90.2 & 9.7 & 9.8 \\
\hline Heat; $80^{\circ} \mathrm{C}$ & 89.6 & 10.3 & 10.4 \\
\hline
\end{tabular}

The stability of Formulation D was assessed at $5^{\circ} \mathrm{C}$ for a period of 12 months and at $25^{\circ} \mathrm{C} \pm 2{ }^{\circ} \mathrm{C}$ under $60 \pm 5 \%$ relative humidity for a period of 6 months. The physical stability parameters including color change, phase separation and loss of water were acceptable throughout the stability period. The cream product was stable over this period with acceptable degradation product formation resulting in more than $95 \%$ of the initial amount of active substance remaining in the sample product. In addition, the cream product was found to be within recommended microbial specification limits throughout the stability period. The stability results comprising $\mathrm{pH}$, drug content and related substance analysis are given in Table 3 and Table 4 . According to results, the cream product was found to be stable at $5^{\circ} \mathrm{C}$ for a period of 12 months and at $25^{\circ} \mathrm{C} \pm 2{ }^{\circ} \mathrm{C}$ under 60 $\pm 5 \%$ relative humidity for a period of 6 months.

Table 3. Stability results for Formulation D initially and after 12 months at $5^{\circ} \mathrm{C}$ storage condition $(n=6)$.

\begin{tabular}{llcccc}
\hline & & \multicolumn{4}{c}{ Time } \\
\cline { 3 - 5 } & & Initially & 3 Months & 6 Months & 12 Months \\
\hline \multirow{2}{*}{ pH } & & $5.24 \pm 0.02$ & $5.85 \pm 0.04$ & $5.63 \pm 0.05$ & $6.05 \pm 0.03$ \\
\multirow{2}{*}{ Assay \% } & Diltiazem & $104.1 \pm 1.8$ & $102.6 \pm 0.95$ & $103.0 \pm 1.1$ & $99.4 \pm 0.42$ \\
& Phenoxyethanol & $101.6 \pm 0.56$ & $100.9 \pm 0.82$ & $101.6 \pm 0.83$ & $98.4 \pm 0.79$ \\
\multirow{2}{*}{$\begin{array}{l}\text { Related } \\
\text { Substance \% }\end{array}$} & $\begin{array}{l}\text { Desacetyl } \\
\text { diltiazem Imp. }\end{array}$ & $0.33 \pm 0.03$ & $0.83 \pm 0.04$ & $1.1 \pm 0.11$ & $1.7 \pm 0.08$ \\
& Total Imp. & $0.35 \pm 0.03$ & $0.85 \pm 0.04$ & $1.1 \pm 0.14$ & $1.7 \pm 0.08$ \\
\hline
\end{tabular}


Table 4. Stability results for Formulation D initially and after 6 months at $25^{\circ} \mathrm{C} \pm 2{ }^{\circ} \mathrm{C}$ under $60 \pm 5 \%$ relative humidity storage condition $(n=6)$.

\begin{tabular}{|c|c|c|c|c|}
\hline & & \multicolumn{3}{|c|}{ Time } \\
\hline & & Initially & 3 Months & 6 Months \\
\hline pH & & $5.24 \pm 0.02$ & $5.91 \pm 0.02$ & $5.58 \pm 0.05$ \\
\hline \multirow{2}{*}{ Assay \% } & Diltiazem & $104.1 \pm 1.8$ & $100.0 \pm 0.76$ & $99.7 \pm 1.2$ \\
\hline & Phenoxyethanol & $101.6 \pm 0.56$ & $101.6 \pm 1.1$ & $101.0 \pm 1.2$ \\
\hline \multirow{2}{*}{$\begin{array}{l}\text { Related } \\
\text { Substance \% }\end{array}$} & $\begin{array}{l}\text { Desacetyl } \\
\text { diltiazem Imp. }\end{array}$ & $0.33 \pm 0.03$ & $2.1 \pm 0.10$ & $2.9 \pm 0.17$ \\
\hline & Total Imp. & $0.35 \pm 0.03$ & $2.1 \pm 0.10$ & $2.9 \pm 0.16$ \\
\hline
\end{tabular}

\section{CONCLUSION}

The objective of this study was to represent the effect of formulation preparation procedure on impurity formation for diltiazem hydrochloride cream formulation. The optimization of Diltiazem $2 \%$ Cream formulation for stability was performed by changing the order of the addition of excipients to the aqueous phase during formulation preparation. The initial procedure of dissolving diltiazem in aqueous phase followed by the addition of excipients resulted in the formation of desacetyl diltiazem impurity during the subsequent mixing of the oil and aqueous phases. The mixing order was changed where diltiazem was added in the final step of the preparation of the aqueous phase, in effect shortening the time diltiazem is subject to mixing. So, desacetyl diltiazem impurity formation decreased. This shows that the formulation procedure clearly affects the amount of degradation product formed during the formulation preparation and indirectly affects the quality of the product.

Product quality tests were performed to assess attributes such as appearance, assay, related substances (degradation products), $\mathrm{pH}$, viscosity and in vitro permeation studies. Quantitative HPLC analysis test was validated according to ICH guidelines.

\section{MATERIALS AND METHODS}

\subsection{Materials}

API grade diltiazem hydrochloride was obtained from Cambrex Profarmaco Milano S.R.L. Propylene glycol, liquid paraffin, cetostearyl alcohol, cetomacrogol 1000 and phenoxyethanol were used as inactive ingredients in formulations. Anoheal ${ }^{\circledR} 2 \%$ Cream (Lot No: 31675$)$ containing diltiazem (reference product) were provided by S.L.A. Pharma Ltd. (UK). Analytical grades of sodium acetate, camphor sulfonic acid, acetonitrile, methanol and phosphate buffer saline (PBS) were used in HPLC analysis. All other chemicals were analytical grade. Ultrapure deionized water was obtained from a Millipore water purification system.

\subsection{Analytical methods}

Quantitative stability indicating HPLC test methods were performed on Waters Alliance HPLC System (Waters, Milford, MA, USA) equipped with the 2695 Separations Module with variable wavelength UVDetector and ran with Empower-2 Software.

Analyses were carried out on C18 column $(300 \times 3.9 \times 5 \mu \mathrm{m})$ using a mobile phase consisting of buffer (0.1 M Sodium Acetate, $0.0046 \mathrm{M}$ of camphor sulfonic-acid $\mathrm{pH}=6.2)$, acetonitrile and methanol $(46: 29: 25 \mathrm{v} / \mathrm{v})$ at a flow rate of $1.5 \mathrm{~mL} / \mathrm{min}$, injection volume $20 \mu \mathrm{l}$ and $\mathrm{UV}$ detection at $240 \mathrm{~nm}$. The column temperature and sample temperature were kept at $45^{\circ} \mathrm{C}$, and $4^{\circ} \mathrm{C}$ respectively. The total analysis run time was 30 minutes.

Sample solution was prepared by dissolving approximately $1 \mathrm{~g}$ of pharmaceutical cream dosage form, equivalent to $20 \mathrm{mg}$ diltiazem hydrochloride in $50 \mathrm{~mL}$ of mobile phase.

The analytical method was validated according to ICH Q2R1 (International Consensus on Harmonization, 2015) with the parameters of selectivity, linearity, limit of detection (LOD), limit of quantitation (LOQ), precision and accuracy according to ICH guidelines. For the selectivity test, HPLC injections of reference standards, sample solution, spiked sample solution and placebo sample solution were performed. Linearity of the method was determined with standard solutions having six different concentration levels between $20 \%$ and $120 \%$. LOD and LOQ values were determined by the standard deviation 
method from the slope $(S)$ of the linearity curve and the standard deviation $(\sigma)$ of the response. They were predicted using following formulas (Eq.1) and (Eq.2);

$$
\begin{aligned}
& \mathrm{LOD}=3.3 \times \mathrm{\sigma} / \mathrm{S} \\
& \mathrm{LOQ}=10 \times \mathrm{\sigma} / \mathrm{S}
\end{aligned}
$$

The precision of the method was evaluated by carrying out preparing standard solutions and cream sample solutions. Relative standard deviations (RSD) of the results were calculated for repeated reference standard injections (system precision) and repeated injections of samples (method precision). RSD was calculated using following formula (Eq.3);

$$
\mathrm{RSD} \%=\mathrm{SD} / \text { Mean } \times 100 \%
$$

Finally, the accuracy of the method was evaluated by analyzing desacetyl diltiazem spiked sample solutions for recovery. The resulting spiked desacetyl diltiazem concentrations corresponded to $0.4 \mu \mathrm{g} / \mathrm{mL}$, $2.0 \mu \mathrm{g} / \mathrm{ml}$ and $2.4 \mu \mathrm{g} / \mathrm{ml}$. The measurements were performed in triplicates. The mean recovery data were calculated using the following formula (Eq.4);

Recovery $\%=$ Concentration measured $/$ Spiked concentration $\times 100 \%$

\subsection{Formulation studies}

Preliminary formulation studies for Diltiazem 2\% Cream formulation were carried out using the same excipients used in the reference product. However, it was determined that a high amount of impurity was formed in the finished product. During these trials, the order of adding excipients during the formulation was determined to have a lot of effect on impurity formation. From that point on, the focus was investigated and the concentrations of the excipients were kept constant to evaluate the effect of mixing order and mixing time of excipients on impurity formation.

In Diltiazem 2\% Cream formulation design, propylene glycol is used as humectant; liquid paraffin is used as emollient; cetostearyl alcohol and cetomacrogol 1000 are used as thickener; glycerol monostearate is used as emulsifier; phenoxyethanol is used as preservative and distilled water is used as solvent. All excipients in the formula are listed in the European Pharmacopoeia and USP monographs and comply with the relevant specifications. Aqueous and oil phases are used to consist the formulation in a general cream formulation and the two phases are mixed to form the final product. Diltiazem was added to the aqueous phase in this formulation, as it is highly soluble and highly permeable and is considered Class I according to the Biopharmaceutical Classification System (BCS). In order to decrease the formation of the degradation product, an optimization study for the aqueous phase was performed. The order of addition of the excipients and the mixing time was studied while the excipient composition keeping constant.

\subsubsection{Preparation of oil phase}

The same oil phase was used for all formulations and was produced as follows; required amount of cetostearyl alcohol, cetomacrogol 1000, liquid paraffin, glycerol monostearate were added to the oil phase boiler and was kept at $70^{\circ} \mathrm{C}$ for 60 minutes. Finally, the prepared oil phase was cooled to $65^{\circ} \mathrm{C}$ and it was used at Formulation $\mathrm{A}$ to $\mathrm{D}$ given below.

\subsubsection{Preparation of Aqueous Phase}

Formulation- $A$ : Water is heated to $65^{\circ} \mathrm{C}$ in the main boiler and diltiazem $\mathrm{HCl}$ is added and mixed for 30 minutes. Then required amount of propylene glycol and phenoxyethanol are added and mixed for 20 minutes at $65^{\circ} \mathrm{C}$ to prepare the aqueous phase.

Formulation-B: Water is heated to $65^{\circ} \mathrm{C}$ in the main boiler and diltiazem $\mathrm{HCl}$ is added and mixed for 20 minutes. Then required amount of propylene glycol and phenoxyethanol are added and mixed for 20 minutes at $65^{\circ} \mathrm{C}$ to prepare the aqueous phase. 
Formulation-C: Required amount of propylene glycol and water are heated to $65^{\circ} \mathrm{C}$ in the main boiler. Diltiazem $\mathrm{HCl}$ and phenoxyethanol are added and mixed for 30 minutes at $65^{\circ} \mathrm{C}$ to prepare the aqueous phase.

Formulation-D: Required amount of propylene glycol and water are heated to $65^{\circ} \mathrm{C}$ in the main boiler. Diltiazem $\mathrm{HCl}$ and phenoxyethanol are added and mixed for 20 minutes at $65^{\circ} \mathrm{C}$ to prepare the aqueous phase.

\subsubsection{Preparation of Diltiazem $2 \%$ Cream}

The mixing step of the oil phase and the aqueous phase was identical for all formulations. The temperature of the oil phase and the aqueous phase was kept at $65^{\circ} \mathrm{C}$. Final cream product was carried out by adding the oil phase to the aqueous phase in the main reactor (Hebold HMW 150 Mixer Semi Solid Production Machine) at $65^{\circ} \mathrm{C}$ with mixing for 30 minutes; then the mixture was homogenized for 15 minutes when it was cooled to $35^{\circ} \mathrm{C}$ under stirring. The ingredients of the cream formulation along with the percentages are listed in Table 5.

Table 5. Composition of diltiazem cream.

\begin{tabular}{lc}
\hline Diltiazem 2\% Cream Formulation & \\
\hline Ingredients & $\mathbf{\%}$ \\
\hline Diltiazem HCl & 2.00 \\
Propylene glycol & 30.00 \\
Liquid Paraffin & 10.00 \\
Cetomacrogol Emulsifying Wax & 5.00 \\
Glycerol Monostearate & 10.00 \\
Phenoxyethanol & 1.00 \\
Water & q.s. \\
\hline
\end{tabular}

\subsection{Performance tests}

\subsubsection{Appearance}

The cream formulations were visually analyzed for color, homogeneity and granular properties.

\subsection{2. $p H$ measurements}

The $\mathrm{pH}$ of the cream formulations were measured with a $\mathrm{pH}$-meter (Mettler Toledo Seven Multi, Switzerland) in order to evaluate suitability for use on damaged skin. The $\mathrm{pH}$ value of undamaged skin is between 5-5.5 and the preferred $\mathrm{pH}$ values required for the topical formulations to be applied on damaged skin is between 5 to 8 [11]. $100 \mathrm{mg}$ of cream was dissolved in $10 \mathrm{ml}$ distilled water and three replicate measurements were performed.

\subsubsection{Viscosity measurements}

The viscosity of cream formulations was measured with Brookfield rotational viscometer using spindle no 96 at a rotation speed of $300 \mathrm{rpm}$ at $25 \pm 2^{\circ} \mathrm{C}$. A minimum of 20 gram cream aliquot was transferred into a beaker and the spindle was run at defined limits. Three replicate measurements were performed.

\subsubsection{Microbiological study}

The microbiological study was carried out according to the European Pharmacopoeia (EP) [12]. According to the EP monograph, the formulation meets microbial requirements if the total aerobic microbial counts are less than $10^{2} \mathrm{cfu} / \mathrm{ml}$ or cfu/g, the total combined yeast/mold counts are less than $10^{2} \mathrm{cfu} / \mathrm{ml}$ or $\mathrm{cfu} / \mathrm{g}$ and if there is no Staphylococcus aureus and no Pseudomonas aeruginosa present.

\subsubsection{In vitro release test (IVRT)}

In vitro release test (IVRT) studies were performed for the comparison of release rates of prepared formulation and reference product by using 6-cell Franz Diffusion apparatus accompanied with thermostatted water circulation. A transdermal diffusion test model Strat-M (Polyether Sulphone) membrane was selected and phosphate buffer saline (PBS) pH 7.4 was used as the receptor medium to fill each diffusion cell. The volume of the diffusion cell is approximately $7 \mathrm{~mL}$. An amount of 400-500 $\mathrm{mg}$ of prepared test product and 
reference product were introduced into the surface of the membrane in the donor compartments with providing sink conditions. During the experiment, the cells were maintained at a constant temperature of $37^{\circ} \mathrm{C}$ $\pm 0.5^{\circ} \mathrm{C}$ while continuously stirred at a constant rate. At the specified time intervals, $0.5 \mathrm{~mL}$ of sample is taken from the receptor compartment and the same amount of receptor medium is added in place in order to maintain the diffusion cell volume for having the proper sink condition. Samples were taken at $0.5,1,2,3,4$, $5,6,7$ and 8 hours after starting the test. All samples were analyzed by the validated HPLC method explained in this study. The cumulative amount of diltiazem released or that permeated through the membrane per area of diffusion was plotted as a function of time.

\subsection{Forced degradation and stability studies}

Forced degradation studies of a drug product were carried out under acidic, alkaline, hydrogen peroxide, heat and humidity stress conditions in order to examine the stability-indicating properties of the method. Acid, base and hydrogen peroxide degradations were performed by dispersing a specific quantity of cream product and placebo in acid ( $1 \mathrm{M}$ of $\mathrm{HCl}$ solution), base (1M of $\mathrm{NaOH}$ solution) or hydrogen peroxide $\left(1 \% \mathrm{H}_{2} \mathrm{O}_{2}\right)$ for 5 hours. Humidity degradation was performed by keeping a specific quantity of cream product and placebo in $40^{\circ} \mathrm{C}$ and $75 \%$ Relative Humidity (RH) for 3 days. In the heat degradation study, cream and placebo were held at $80^{\circ} \mathrm{C}$ for 3 days. The samples were allowed to cool to room temperature and analyzed for desacetyl diltiazem against a control sample.

The storage stability conditions were based according to the storage information of the reference product which is instructed to be stored at $2-8^{\circ} \mathrm{C}$ and away from direct heat and light. To evaluate physical and chemical stability, the prepared formulation kept in an aluminum tube was stored for 12 months at $5{ }^{\circ} \mathrm{C}$ and 6 months at $25^{\circ} \mathrm{C} \pm 2{ }^{\circ} \mathrm{C}$ under $60 \pm 5 \%$ relative humidity. Physical stability was examined by observing color change, phase separation and water loss. Chemical stability was examined by measuring $\mathrm{pH}$ and quantification of drug content and related substances. Samples were withdrawn at pre-determined intervals and analyzed. As reported in European Pharmacopeia 10.0, the amount of active substance should not decrease to below $95 \%$ of the initial amount.

Acknowledgements: This study was supported by ILKO Pharmaceuticals. The authors thank ILKO Pharmaceuticals $R \& D$ Center colleagues for their contributions to this research.

Author contributions: Concept - B.KÖ., B.B., A.AD., O.P.; Design - B.KÖ., B.B. A.AD., O.P.; Supervision - A.AD., O.P.; Resources - B.KÖ., B.B. A.AD., O.P.; Materials - B.KÖ., B.B.; Data Collection and/or Processing - B.KÖ., B.B., A.AD., O.P.; Analysis and/or Interpretation - B.KÖ., B.B., A.AD., O.P.; Literature Search - B.KÖ., B.B., N.S., A.AD., O.P.; Writing - N.S.; Critical Reviews - B.KÖ., B.B., N.S., A.AD., O.P.

Conflict of interest statement: The authors declared no conflict of interest.

\section{REFERENCES}

[1] Pereira CEDO, Nogueira FHA, Pianetti GA. Development and validation of a stability indicating HPLC method to determine diltiazem hydrochloride in tablets and compounded capsules. Braz J Pharm Sci. 2017; 53(3). [CrossRef]

[2] Kumar BMS, Rajkamal B, Chandramowli B. A validated RP-HPLC method for the determination of diltiazem in raw material and pharmaceutical dosage form. Int J Pharm Sci Drug Res. 2018; 10(6): 487-491. [CrossRef]

[3] Buur JL, Baynes RE, Yeatts JL, Davidson G, DeFrancesco TC. Analysis of diltiazem in Lipoderm ${ }^{\circledR}$ transdermal gel using reversed-phase high-performance liquid chromatography applied to homogenization and stability studies. J Pharm Biomed Anal. 2005; 38(1): 60-65. [CrossRef]

[4] NICE, National Institude for Health and Care Excellence. Chronic anal fissure: 2\% Topical diltiazem hydrochloride. https://www.nice.org.uk/advice/esuom3/resources/2-topical-diltiazem-hydrochloride-for-chronic-anal-fissurepdf-17548582597 (accessed on 14 January 2020).

[5] Shah M, Sandler L, Rai V, Sharma C, Raghavan L. Quality of compounded topical 2\% diltiazem hydrochloride formulations for anal fissure. World J Gastroenterol. 2013; 19(34): 5645-5650. [CrossRef]

[6] Dhawan S, Chopra S. Nonsurgical approaches for the treatment of anal fissures. Am J Gastroenterol. 2007; 102: 13121321. [CrossRef]

[7] Diltiazem hydrochloride 2\% cream leaflet. https://www.slapharma.com/wp-content/uploads/2019/07/MI-1Anoheal-Patient-Information-Leaflet-Mar07.pdf (accessed 16 January 2020) 
[8] Griffin N, Acheson AG, Jonas M, Scholefield JH. The role of topical diltiazem in the treatment of chronic anal fissures that have failed glyceryl trinitrate therapy. Colorectal Dis. 2002; 4(6): 430-435. [CrossRef]

[9] Alexandre Miguel VAR, Isabel Maria CDA. Stable diltiazem hydrochloride pharmaceutical composition for cutaneous application and process for the preparation thereof. EP Patent 1516622 A1; 2003.

[10] Conjeevaram R, Dubash D, Salpekar A. Topical pharmaceutical compositions comprising calcium-channel blocker and method of using same. WO Patent 2008/022032 A2; 2007.

[11] Risaliti L, Piazzini V, Di Marzo MG, Brunetti L, Cecchi R, Lencioni P, Bilia AR, Bergonzi MC. Topical formulations of delta-aminolevulinic acid for the treatment of actinic keratosis: Characterization and efficacy evaluation. Eur J Pharm Sci. 2018; 115: 345-351. [CrossRef]

[12] European Pharmacopeia 7.0. Efficacy of antimicrobial preservation, European Department for the Quality of Medicines within the Council of Europe, Strasbourg, section 5.1.3, 2009:528-9.

This is an open access article which is publicly available on our jour nal's website under Institutional Repository at http://dspace.marmara.edu.tr. 